\title{
Pathogenic mechanisms and clinical implications of congenital neutropenia syndromes
}

\author{
Fabian Hauck and Christoph Klein
}

\begin{abstract}
Purpose of review
The purpose of this review is to summarize pathogenic mechanisms and clinical implications of the most illustrative genetic entities of congenital neutropenia syndromes.
\end{abstract}

\begin{abstract}
Recent findings
Congenital neutropenia comprise monogenetic entities with or without additional immunologic and extrahaematopoietic syndromatic features. Continuous careful explorations of known entities such as ELANE, GFI1, HAX1, G6PC3 deficiency and XLN help to define principles controlling differentiation and function of neutrophil granulocytes. Furthermore, the identification of novel genetic defects associated with congenital neutropenia, such as VPS45 deficiency, broadens our understanding of neutrophil biology. Pathogenic mechanisms imply protein and vesicle mistrafficking, endoplasmic reticulum stress, the unfolded protein response, destabilization of the mitochondrial membrane potential, disturbed energy metabolism, dysglycosylation and deregulated actin polymerization.
\end{abstract}

\begin{abstract}
Summary
Advanced genetic and biochemical techniques have helped to expand our knowledge of congenital neutropenia syndromes. Known and novel genetic entities shed light on fundamental biological processes important for the homeostatis and functioning not only of the neutrophil granulocyte but as well of the entire haematopoietic system. Furthermore, treatment decisions become more tailored and might pave the road towards personalized molecular medicine.
\end{abstract}

\section{Keywords}

elastase neutrophil expressed, glucose 6 phosphatase catalytic subunit 3, growth factor independent 1 transcription repressor, haematopoietic cell specific LYN substrate 1 associated protein X-1, severe congenital neutropenia, vacuolar protein sorting 45 homolog, X-linked neutropenia

\section{INTRODUCTION}

Neutrophil granulocytes are the most abundant type of leukocytes and their inherited quantitative disorders are referred to as congenital neutropenia with or without additional immunologic and extrahaematopoietic manifestations (Table 1 [1-14,15", 16-41,42"',43-53,54",55-61,62"',63",64"',65-76, 77",78-95,96"',97-102]). The absolute neutrophil count (ANC) in the peripheral blood is used for dividing congenital neutropenia into mild (1.0$\left.1.5 \times 10^{9} / 1\right)$, moderate $\left(0.5-1.0 \times 10^{9} / 1\right)$ and severe $\left(<0.5 \times 10^{9} / 1\right)$ subtypes. Neutropenia may be constant, intermittant or periodic such as in cyclic neutropenia $(\mathrm{CyN})$. Frequently, in congenital neutropenia, compensatory monocytosis is seen [103",104-106].

Patient registries founded in the early 1990s have allowed calculating an estimated incidence of $10-15 / 1 \times 10^{6}$ birth and a prevalence of more than $10 / 1 \times 10^{6}$ inhabitants. Concerted international collaborations have facilitated the discovery of genetic defects associated with severe congenital neutropenia $(\mathrm{SCN})$. However, even in the era of next-generation sequencing, the genetic cause of congenital neutropenia remains unknown in $30-50 \%$ of patients [107"].

Clinically, congenital neutropenia are characterized by acute and life-threatening invasive bacterial and fungal infections such as cellulitis, pneumonia and sepsis and chronic stomatologic infections such as recurrent aphthosis, paradontopathy and tooth

Dr von Hauner Children's Hospital, Ludwig-Maximilians-University Munich, Munich, Germany

Correspondence to Christoph Klein, Dr von Hauner University Children's Hospital, Lindwurmstrasse 4, 80337 Munich, Germany. Tel: +49 89 5160 7700; fax: +49 895160 7702; e-mail: christoph.klein@med.unimuenchen.de

Curr Opin Allergy Clin Immunol 2013, 13:596-606

DOI:10.1097/ACI.0000000000000014 


\section{KEY POINTS}

- Congenital neutropenia comprises monogenetic entities with or without additional immunologic and extrahaematopoietic manifestations.

- Pathogenic mechanisms imply RNA processing, protein and vesicle mistrafficking, endoplasmic reticulum stress, the unfolded protein response, destabilization of the mitochondrial membrane potential, disturbed energy metabolism and dysglycosylation, as well as deregulated actin polymerization.

- Molecular diagnosis is important for risk stratification, treatment choice and prognosis.

loss [107"]. Moreover, congenital neutropenia is considered a premalignant state of haematopoietic stem or progenitor cells and may degenerate into myelodysplastic syndrome (MDS) and acute myeloblastic leukaemia (AML) $[108,109]$.

Granulocyte colony stimulating factor (G-CSF), which has been commercially available since 1993, has emerged as an effective first-line treatment and importantly reduced the mortality of congenital neutropenia [110,111]. However, a cumulative G-CSF dose of more than $10000 \mu \mathrm{g} / \mathrm{kg}$ and a mean G-CSF dose per injection of more than $10 \mu \mathrm{g} / \mathrm{kg}$ are significantly related to malignant transformation $[108,109]$. The individual phenotype and the risk of malignancy vary for each genetic subtype of congenital neutropenia [112].

\section{MAJOR PROGRESS}

Qualitative neutrophil disorders such as myeloperoxidase deficiency (MPD), chronic granulomatous disease (CGD) and leukocyte adhesion deficiencies (LADs) are reviewed in great depth elsewhere. This review focuses on recent major progress in science on diseases associated with reduced numbers of neutrophil granulocytes [113"-115"].

\section{BENIGN NEUTROPENIA}

Benign neutropenia is a mild to moderate $\left(0.5-1.5 \times 10^{9} / 1\right)$ congenital neutropenia without numerical or morphological bone marrow abnormalities and without increased risk of bacterial or fungal infections $\left[14,15^{\prime}, 116,117\right]$. Benign neutropenia is prevalent in approximately $4.5 \%$ of black and $0.8 \%$ of white Americans and can be found in the Arabian Peninsula and in various European regions as well [118-120].

In individuals from geographic regions where Plasmodium spp. are endemic, benign neutropenia is associated with an autosomal recessive promotor polymorphism in the Duffy blood group chemokine receptor gene $(D A R C$ c.T- $46>C)$ that abrogates the binding of the transcription factor GATA binding protein 1 (GATA1) and leads to a loss of DARC expression on erythrocytes [1-3]. Even though the resulting Duffy null blood group has been found protective against Plasmodium vivax infection and is associated with an increased susceptibility towards human immunodeficiency virus (HIV) infection, the precise molecular mechanism of benign neutropenia remains elusive $\left[4-6,121^{\circ}\right]$. Current attempts to explain the phenotype of benign neutropenia often invoke nonhaematopoietic cells such as the endothelium and consecutive aberrant response to chemokines and transendothelial migration of neutrophil granulocytes [122,123].

Genome-wide association studies (GWAS) $\left[124,125^{*}\right]$ for benign neutropenia in the remaining ethnicities have identified a locus on chromosome $17 \mathrm{q}$ and further genetic regions.

\section{ELANE DEFICIENCY}

Heterozygous mutations in the elastase neutrophil expressed gene (ELANE) coding for the neutrophil elastase cause $\mathrm{CyN}$ and SCN type 1 (SCN1) in an autosomal dominant way and are the most common cause of congenital neutropenia in the Caucasian population (41\% in Europeans and 55.6\% in North Americans) $[7,8]$. More than 100 defined genetic variants in ELANE have been associated with SCN1 [126"'].

CyN is characterized by an ANC that oscillates with a periodicity of approximately 21 days between almost normal values and complete disappearance of neutrophil granulocyte and that exhibits a reverse monocyte cycling, that is monocytes increase when neutrophil granulocytes decrease [9]. SCN1, however, displays a permanent bone marrow maturation arrest at the promyelocyte stage [7].

Even though specific ELANE mutations may lead to $\mathrm{CyN}$ and SCN1, respectively, there is no established firm genotype-phenotype correlation and we face a continuum rather than a clear-cut separation $[7,8,10]$. This might be due to inappropriate ANC monitoring, G-CSF treatment related cycle modification, incomplete mutation spectrum data, phenotype diversification by modifier genes and additional somatic mutations, especially in the colony stimulating factor 3 receptor gene (CSF3R) $\left[11-14,15^{\prime \prime}, 127,128\right]$.

Nevertheless, on the basis of recent findings, several general conclusions may be justified. First, all known mutations lead to protein expression, so mere haploinsufficiency is not causing ELANE 


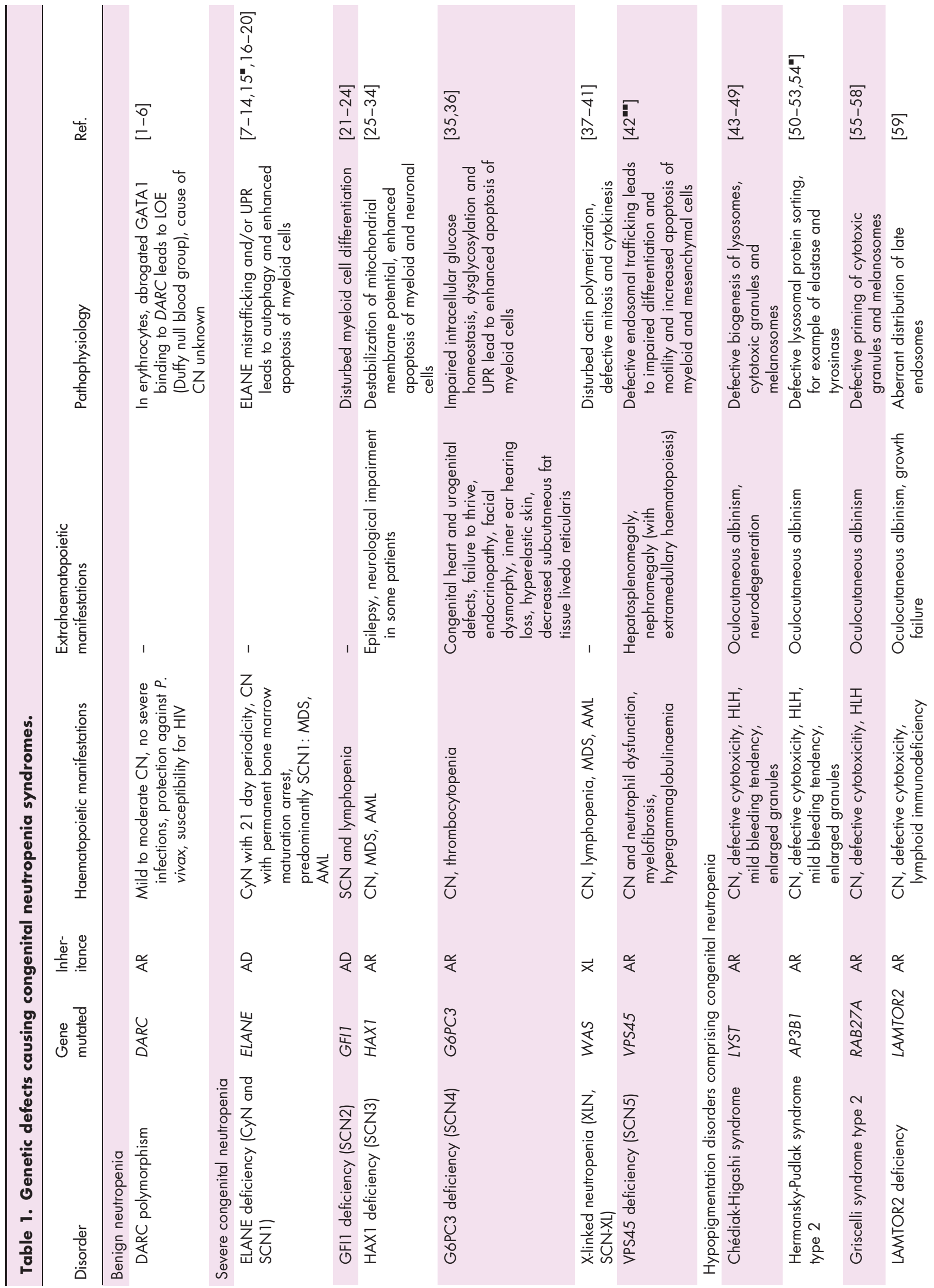




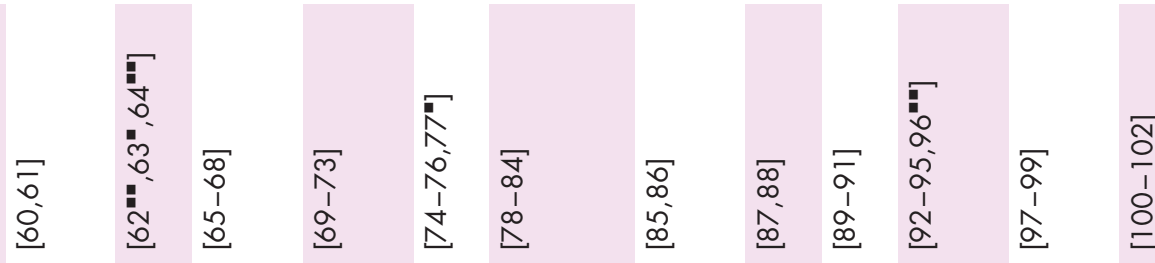
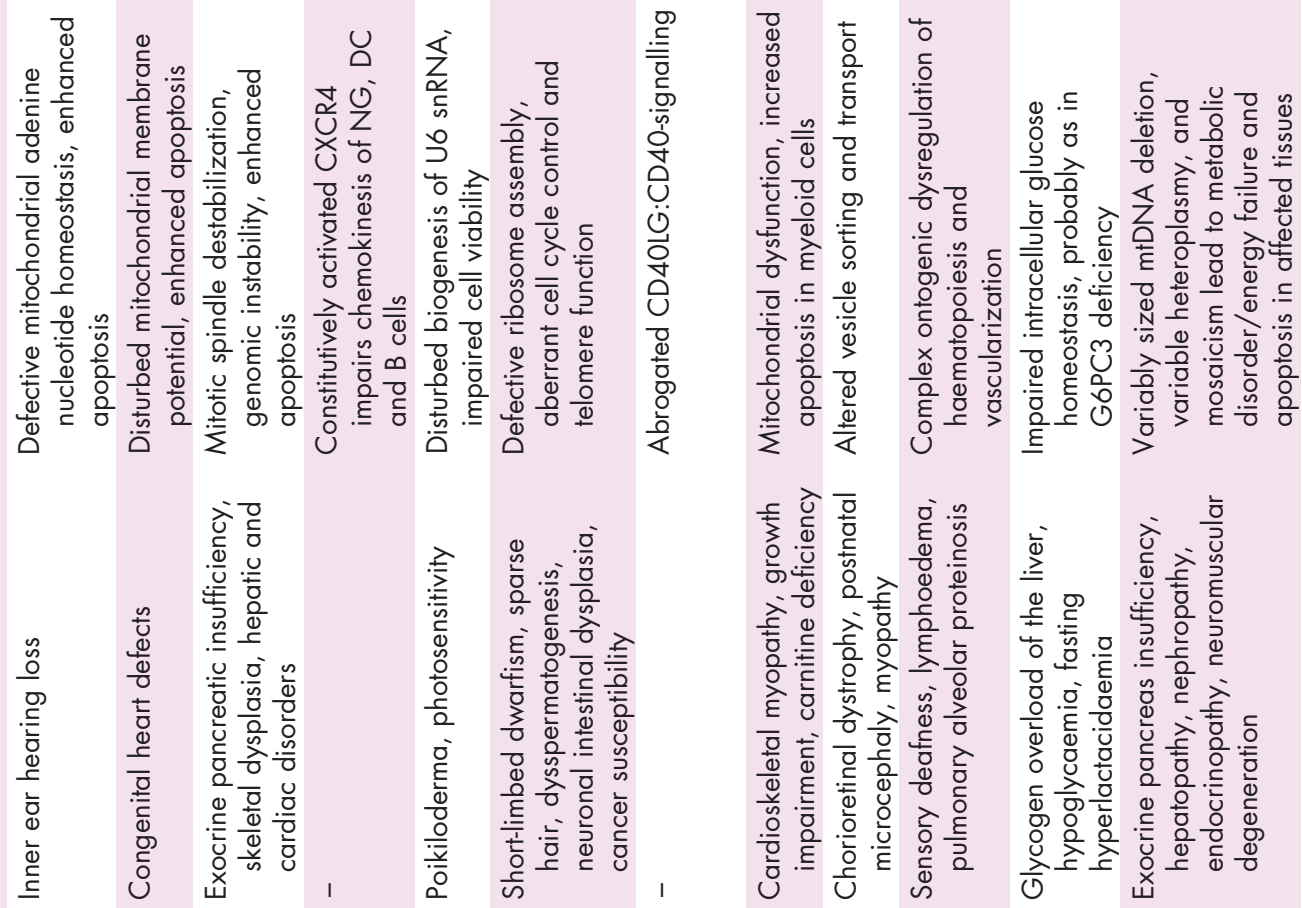

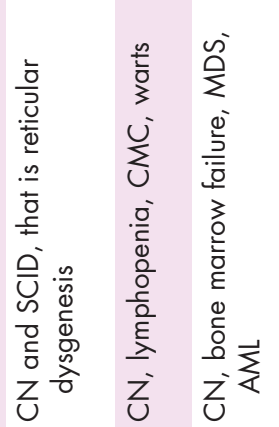
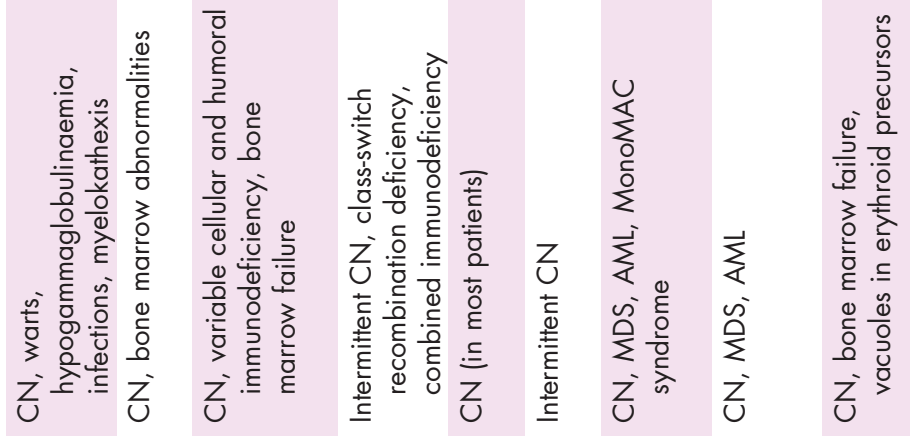



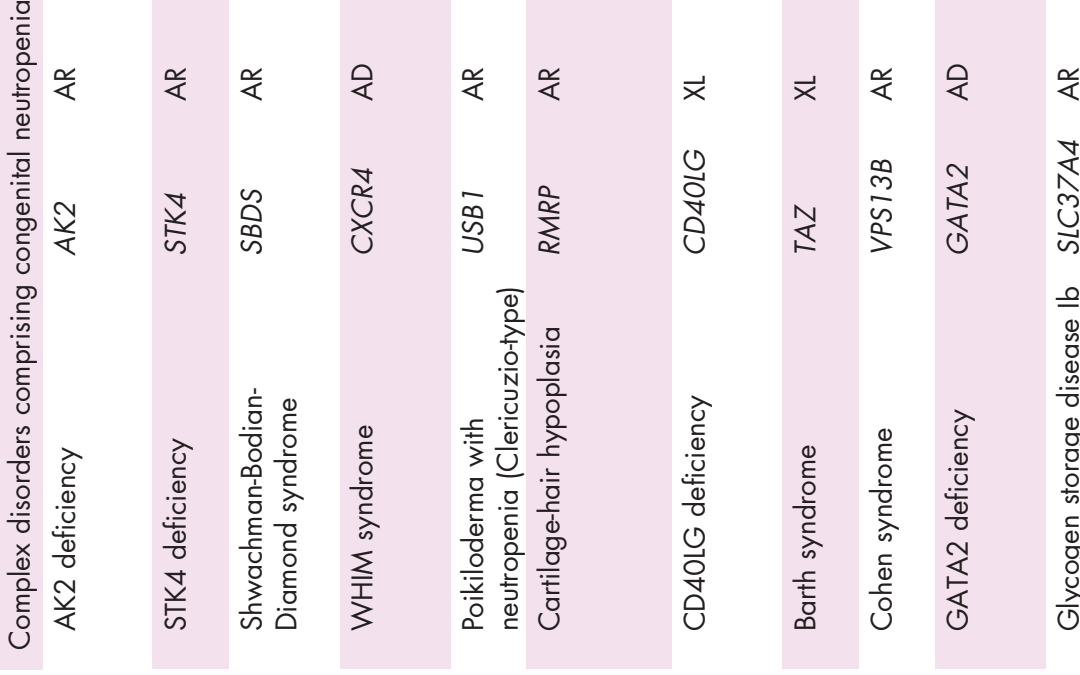


deficiency. Second, truncating mutations in the terminal exon 5 lead to expression of neutrophil elastase that lacks a binding site for the adaptor protein 3 (AP3) and are predominantly associated with SCN1. Third, missense mutations of the consensus splice acceptor in intron 4 lead to the use of a cryptic splice site in exon 5 and to the deletion of the catalytic site ( $\Delta 161-170)$ and are predominantly associated with CyN. Fourth, the common p.G815R mutation leads to G-CSF-refractory SCN1 with frequent progression to MDS and AML $\left[15^{\circ}, 16,17\right]$.

The monomeric serine chymotryptic-type protease neutrophil elastase is a major component of neutrophil granulocyte azurophilic granules and is named after its first known substrate elastin [129]. Neutrophil elastase is synthesized as an inactive zymogen of 267 amino acid (aa) residues and is activated by limited proteolysis at both its amino and carboxyterminus. The cleavage of the N-terminal 27 aa pre and two aa pro-signalling sequences and a C-terminal 20 aa propeptide is fundamental to neutrophil elastase trafficking and enzymatic function [130,131]. Neutrophil elastase targets a variety of bacterial virulence factors and processes cytokines, chemokines, G-CSF and G-CSFR. Thus, it is involved in bacterial killing and in various signalling and homeostatic circuits [132,133]. Activated neutrophil elastase is kept in check by serine proteinase inhibitors, that is serpins, such as $\alpha 1$-protease inhibitor [134].

How exactly ELANE mutations lead to CyN and SCN1 remains a matter of debate and the three principal hypotheses that have emerged are not mutually exclusive. The inhibitor hypothesis assumes that ELANE mutations produce a negative feedback loop that leads to periodic impairment of neutrophil production and differentiation and uses mathematical models to demonstrate the 21-day periodicity of $\mathrm{CyN}$ [135].

The mislocalization hypothesis posits that neutrophil elastase is an AP3-cargo and trafficking through the trans-Golgi network towards the azurophilic granules is hampered as a consequence of C-terminal (truncating) mutations. Consequently, neutrophil elastase devoid of correct posttranslational processing accumulates in erroneous subcellular compartments $[16,18,19]$. How this interferes with (cyclic) neutrophil maturation arrest is not resolved and the answer might, at least partially, come from the unfolded protein response (UPR) hypothesis.

The UPR hypothesis proposes that ELANE mutations lead to neutrophil elastase misfolding during protein biosynthesis and cause an endoplasmic reticulum stress response as deduced by the upregulation of the stress marker heat shock 70-kDa protein 5 (HSPA5) and the splicing of
X-box-binding protein 1 (XBP1) mRNA. Endoplasmic reticulum stress then initiates autophagy or apoptosis of neutrophil granulocyte and causes SCN1 as illustrated in cell culture systems and transgenic murine models $[19,20,136]$.

Even though it has become clear the ELANE mutation induced cell death is pivotal for the phenotype of congenital neutropenia, it is still unclear which factors determine $\mathrm{CyN}$ versus SCN1, why G-CSF treatment can overcome the observed maturation arrest and why MDS and AML preferentially develop in SCN1, but are scarce in CyN. It is noteworthy that leukaemogenesis in SCN1 can proceed as a consequence of somatic CSF3R mutations. The very mechanisms that deviate ELANE mutations towards CyN versus SCN1 may also control the threshold for selective pressure and additional somatic hits required for clonal outgrowth of leukaemia cells [137"].

\section{GFI1 DEFICIENCY (SCN2)}

Very rarely, congenital neutropenia has been found to be associated with mutations in the transcription factor growth factor independent 1 transcription repressor (GFI1). A murine knockout model for the growth factor independent 1 gene (Gfi1) has been found to cause myeloid differentiation arrest and to lead to SCN as well $[138,139]$. In addition, the differentiation and function of further haematopoietic lineages such as dendritic cells, B cells and $\mathrm{T}$ helper cells are disturbed in Gfi1-deficient mice [140-143]. Gfi1 is a predominantly repressive zincfinger transcription factor that governs haematopoietic stem cell homeostasis and especially myeloid differentiation by regulating a plethora of biological processes such as trancriptional networks, microRNA processing and degradative ubiquitinationmediated apoptosis [144-147].

Almost paralleling these findings, heterozygous human mutations in GFI1 leading to the dominant negative p.N382S and p.K403R substitutions and reducing the expression level of neutrophil elastase have been described to cause SCN2 with an additional lymphocyte proliferation defect [21,22]. Mechanistically, NEDD4-binding protein 2-like 2 (N4BP2L2) has been shown to interact with neutrophil elastase and GFI1 and might link GFI1 mutations to reduced ELANE expression in SCN2, even though there has not yet been any N4BP2L2 mutation found in SCN [23].

Interestingly, the very same mutations have been found as monoallelic de-novo mutations in one patient presenting with $\mathrm{CyN}$. The authors found cycling cytotoxic $\mathrm{T}$ cell responses against HLA-A2 presented neutrophil elastase epitopes as causing 
this autoimmune $\mathrm{CyN}$ and their study [24] expands the pathogenetic mechanisms probably leading to $\mathrm{CyN}$.

\section{HAX1 DEFICIENCY (SCN 3)}

Autosomal recessive mutations in haematopoietic cell specific LYN substrate 1 (HCLS1)-associated protein X-1 (HAX1) cause SCN3, classically known as Kostmann disease, and contribute to approximately $15 \%$ of SCN with a preponderance in the Turkish and Middle Eastern population $[25,26,148]$.

HAX1 deficiency is characterized by SCN (often $\left.<0.2 \times 10^{9} / 1\right)$ resulting from a maturation arrest at the promyelocyte stage and presenting during the first weeks of life with severe and life-threatening bacterial infections [27]. Some patients additionally display neurological impairment such as mental retardation and epilepsy and this is thought to result from $H A X 1$ mutations that do not only affect isoform A but also isoform B $[28,29]$. However, there might be a more complex genotype-phenotype relation, because compound heterozygous HAX1 mutations targeting both transcripts have been described in SCN3 patients not affected by neuropathology [149,150"'].

HAX1 was initially identified as a ubiquitously expressed binding partner of HCLS1, which is involved in SRC-kinase signalling downstream of the B cell antigen receptor (BCR) [30]. HAX1 is an intracellular $35-\mathrm{kDa}$ protein that predominantly localizes to the mitochondria but that can be detected in the endoplasmic reticulum and nuclear envelopes as well [30]. Biochemical analyses established a role of HAX1 in stabilizing the mitochondrial membrane potential $(\Delta \psi \mathrm{m})$ and were congruent with increased apoptosis observed in HAX1-deficient myeloid and extrahaematopoietic cells [26,31]. HAX1 interacts with presenilin-associated rhomboid-like (PARL) and HtrA serine peptidase 2 (HTRA2) that activate the pro-apoptotic BCL2-associated $\mathrm{X}$ protein (BAX) pathway [31,32]. In addition, HAX has been shown to protect the antiapoptotic X-linked inhibitor of apoptosis (XIAP) from ubiquitination-mediated proteasomal degradation [33]. Further evidence for an antiapoptotic role of HAX1 stems from the observation that it interacts with and downregulates the protein level of ATPase $\mathrm{Ca}^{2+}$ transporting cardiac muscle slow twitch 2 (ATP2A2) that regulates the endoplasmic reticulum $\mathrm{Ca}^{2+}$-concentration [34].

In line with an important function for HAX1 in cellular homeostatis is the observation that a number of viruses such as Epstein-Barr virus (EBV), human herpesvirus 8 (HHV-8), HIV and hepatitis $\mathrm{C}$ virus $(\mathrm{HCV})$, which partially establish latency, code for HAX-1 interacting proteins, even though the mechanistic consequences of these interactions remain elusive [151-156].

Additional HAX1-protein interactions that are coupled to particular biological processes have been elucidated and it seems that HAX1 is involved in Ras homolog family member A (RHOA) mediated neutrophil cell adhesion and migration as well as in posttranscriptional mRNA processing, stability and localization $[157,158]$.

Taken as a whole, HAX1 seems to balance proapoptotic and antiapoptotic signalling networks and to modulate further biological processes, but the precise mechanisms of increased apoptosis in developing myeloid cells have still to be determined.

\section{G6PC3 DEFICIENCY (SCN4)}

Autosomal recessive mutations in glucose 6 phosphatase catalytic subunit 3 (G6PC3) cause SCN4, a predominantly quantitative disorder of neutrophil granulocytes with variable thrombocytopenia and associated syndromatic features [159,160"']. The most common extrahaematopoietic manifestations of G6PC3 deficiency comprise congenital heart and urogenital defects, failure to thrive, endocrine disorders, facial dysmorphy, inner ear hearing loss, hyperelastic skin, decreased subcutaneous fat tissue and livedo reticularis [160"']. Mutations in G6PC3 cluster in exons 1 and 6 , which are coding for the $\mathrm{C}$ and N-terminus of G6PC3, respectively. However, the current mutational spectrum in a limited number of patients has not yet allowed a clear genotypephenotype correlation [160"'].

G6PC3 is a ubiquitously expressed metabolic enzyme of the glucose 6 phosphatase (G6P) family, that is G6PC1-3, which localizes to the endoplasmic reticulum membrane where it is supposed to form a functional complex with glucose-6-phosphate transporter (G6PT), also known as solute carrier family 37 member 4 (SLC37A4) [161,162]. Neutrophil granulocyte G6PC3 deficiency deranges glucose recycling between the endoplasmic reticulum and the cytoplasm and leads to reduced levels of glucose uptake and its energy-carrying catabolites obtained by glycolysis [163]. In an experimental setting, this metabolic starving induces pronounced apoptosis of peripheral neutrophil granulocyte, whereas other haematopoietic lineages are less affected [159]. Mechanistically, a nutrient-sensitive network governed by the proapoptotic and antiapoptotic molecules glycogen synthase kinase 3 beta (GSK3B) and myeloid cell leukaemia sequence 1 (MCL1), respectively, in case of starvation targets the outer mitochondrial membrane and induces the intrinsic apoptotic pathway $[164,165]$. 
Importantly, defective endoplasmic reticulum glucose metabolism additionally interferes with proper glycosylation patterns of various proteins, such as components of the NADPH oxidase, which are important for neutrophil granulocyte functioning [35]. Furthermore, apoptosis in G6PC3-deficient myeloid cells might be linked to the UPR, but whether this is linked to dysglycosylation has not yet been examined [160"'].

In G6pc3-deficient murine neutrophil granulocytes, metabolic alterations and increased apoptosis can be counteracted by application of G-CSF [36]. It is tempting to speculate that the favourable clinical response towards G-CSF reported for G6PC3deficient patients might follow similar correction mechanisms [160"']. Currently, for G6PC3 deficiency, no malignant transformation has been reported, and in light of the particular pathogenesis and comorbidity, this might be an important feature of SCN4 and influence our therapeutic approach [160"'].

\section{X-LINKED NEUTROPENIA}

Mutations inactivating the Wiskott-Aldrich syndrome (WAS) gene product Wiskott-Aldrich syndrome protein (WASP) cause classical WiskottAldrich syndrome (WAS) or X-linked thrombocytopenia (XLT). WAS and XLT determine a spectrum rather than two distinct nosological entities $[166,167]$. The former is characterized by lymphoid and myeloid immunodeficiency, autoimmunity, predisposition to malignant lymphoma, eczema and microthrombocytoepnia, while the latter presents predominantly with microthrombocytoepenia and bleeding diathesis $[166,167]$.

WASP is central to actin dynamics and in the haematopoietic system couples the membrane-proximal signalling layer to the cytoskeletal layer [168]. Consequently, a variety of cellular processes such as immunological synapse and kinapse formation, TCR and BCR signalling, integrin inside-out signalling, vesicle trafficking and cellular morphogenesis are critically hampered [169]. An important means of WASP regulation is an autoinhibitory conformation that is based on an intramolecular interaction between the verprolin homology domain-cofilin homology domain-acidic region (VCA) and the GTPase-binding domain (GBD). This closed conformation interferes with binding of the actin-related protein 2/3 (ARP2/3) complex and with monomeric actin to the carboxyl terminus of WASP [169].

Contrasting to WAS and XLT wherein inactivating WASP mutations lead to absent or residual protein expression, activating WASP mutations that target the GBD and interfere with autoinhibition cause X-linked neutropenia (XLN, SCN-XL) [37-39]. Constitutively active WASP results in intensified and misplaced actin polymerization and results in defective mitosis and cytokinesis as well as apoptosis-prone proliferation, especially in myeloid lineages [40]. Apart from neutropenia and monocytopenia, XLN shows reduced natural killer (NK) and $\mathrm{T}$ cell counts, impaired $\mathrm{T}$ cell proliferation and a genomic instability with a predisposition to MDS [38-41].

In summary, distinct WAS mutations lead to various disease entities and impressively highlight the multifaceted biological roles of WASP at the interface of the membrane-proximal signalling layer with the cytoskeletal layer in the haematopoietic system.

\section{VPS45 DEFICIENCY (SCN-5)}

Lately, autosomal recessive mutations in vacuolar protein sorting 45 homolog (VPS45) have been ascribed to a congenital neutrophil defect syndrome (SCN5) in seven patients from five consanguineous families [42"'].

VPS45 controls membrane trafficking through the endosomal system and defective endosomal trafficking and protein sorting/recycling appear to be the pathogenic mechanisms $\left[42^{-"}, 170,171\right]$.

Elegant phenotypic and functional analyses performed with VPS45-deficient primary neutrophil granulocyte and fibroblasts found quantitative and qualitative neutrophil impairments due to hampered development, decreased motility and increased apoptosis of myeloid and mesenchymal cells [42"-]. In addition, complementation assays reversed the phenotype in fibroblasts and a morpholino-injected zebrafish model recapitulated the SCN found in man [109].

Clinically, the patients presented SCN, thrombocytopenia, and anaemia, the latter probably due to an important myelofibrosis. In addition, extramedullary haematopoiesis leads to hepatosplenomegaly and nephromegaly [42"']. All patients were refractory to G-CSF treatment, and in one of the affected kindred, additional neurodevelopmental sequelae were noted [42"'].

VPS45 deficiency highlights the importance of vesicle trafficking in the haematopoietic system, but especially the pathogenic mechanism of myelofibrosis awaits further clarification.

\section{POIKILODERMA WITH NEUTROPENIA (CLERICUZIO-TYPE)}

Mutations in the U6 snRNA biogenesis 1 (USB1) gene cause an autosomal recessive genodermatosis that 
associates poikiloderma, that is erythematous rash, irrregular skin pigmentation, teleangiectasia and hyperkeratosis, with neutropenia (PN), bone marrow and peripheral blood abnormalities $[74,75]$. The syndrome was first described by Clericuzio in Navajo Indians and consecutively found in Apache Indians and other kindred $[74,76,172]$. Infrequently, short stature, nail dystrophy and MDS have been reported as well [173].

USB1 is a phosphodiesterase and its yeast ortho$\log$ is involved as a RNA exonuclease in posttranslational processing of spliceosomal small nuclear RNA (snRNA) that is important for cell viability [77"]. The clinical phenotype of PN overlaps with those of dyskeratosis congenita and Rothmund-Thomson syndrome (RTS), and even though in PN telomere shortage has not yet been described, this might be a common pathomechanism $[173,174]$.

\section{CONCLUSION}

With the advent of joint databases, commonly available G-CSF treatment and advanced genetic and biochemical techniques, our knowledge of congenital neutropenia syndromes is constantly growing. Novel genetic entities pinpoint towards fundamental biological processes important for the homeostatis and functioning not only of the neutrophil granulocyte but also of the haematopoietic system and its niche. Even though not all aspects of molecular pathogenesis have been elucidated up to now, treatment decisions, that is G-CSF application versus haematopoietic stem cell transplantation, become more sophisticated and might open up into personalized molecular medicine.

\section{Acknowledgements}

We value the personal, clinical and scientific contributions of the patients, their families and our colleagues. We acknowledge the SCN registries in Germany and France and the international Care-for-Rare Alliance. This work was partially supported by the Erare NeutroNET grant.

\section{Conflicts of interest}

There are no conflicts of interest.

\section{REFERENCES AND RECOMIMENDED \\ READING}

Papers of particular interest, published within the annual period of review, have been highlighted as:

- of special interest

- of outstanding interest

1. Peiper SC, Wang ZX, Neote $K$, et al. The Duffy antigen/receptor for chemokines (DARC) is expressed in endothelial cells of Duffy negative individuals who lack the erythrocyte receptor. J Exp Med 1995; 181:13111317.
2. Reich $D$, Nalls $M A, K a o W H$, et al. Reduced neutrophil count in people of African descent is due to a regulatory variant in the Duffy antigen receptor for chemokines gene. PLoS Genet 2009; 5:e1000360.

3. Tournamille C, Colin Y, Cartron JP, Le Van Kim C. Disruption of a GATA motif in the Duffy gene promoter abolishes erythroid gene expression in Duffynegative individuals. Nat Genet 1995; 10:224-228.

4. Horuk R, Chitnis CE, Darbonne WC, et al. A receptor for the malarial parasite Plasmodium vivax: the erythrocyte chemokine receptor. Science 1993; 261:1182-1184.

5. Miller LH, Mason SJ, Clyde DF, McGinniss MH. The resistance factor to Plasmodium vivax in blacks: the Duffy-blood-group genotype, FyFy. N Engl J Med 1976; 295:302-304.

6. Ramsuran V, Kulkarni $\mathrm{H}, \mathrm{He} W$, et al. Duffy-null-associated low neutrophil counts influence HIV-1 susceptibility in high-risk South African black women. Clin Infect Dis 2011; 52:1248-1256.

7. Dale DC, Person RE, Bolyard AA, et al. Mutations in the gene encoding neutrophil elastase in congenital and cyclic neutropenia. Blood 2000; 96:2317-2322.

8. Horwitz M, Benson KF, Person RE, et al. Mutations in ELA2, encoding neutrophil elastase, define a 21-day biological clock in cyclic haematopoiesis. Nat Genet 1999; 23:433-436.

9. Lange RD. Cyclic hematopoiesis: human cyclic neutropenia. Exp Hematol $1983 ; 11: 435-451$.

10. Thusberg J, Vihinen M. Bioinformatic analysis of protein structure-function relationships: case study of leukocyte elastase (ELA2) missense mutations. Hum Mutat 2006; 27:1230-1243.

11. Germeshausen $M$, Zeidler $C$, Stuhrmann $M$, et al. Digenic mutations in severe congenital neutropenia. Haematologica 2010; 95:1207-1210.

12. Lanciotti M, Caridi G, Rosano $C$, et al. Severe congenital neutropenia: a negative synergistic effect of multiple mutations of ELANE (ELA2) gene. Br J Haematol 2009; 146:578-580.

13. Newburger PE, Pindyck TN, Zhu Z, et al. Cyclic neutropenia and severe congenital neutropenia in patients with a shared ELANE mutation and paternal haplotype: evidence for phenotype determination by modifying genes. Pediatr Blood Cancer 2010; 55:314-317.

14. Salipante SJ, Benson KF, Luty J, et al. Double de novo mutations of ELA2 in cyclic and severe congenital neutropenia. Hum Mutat 2007; 28:874881 .

15. Horwitz MS, Corey SJ, Grimes HL, Tidwell T. ELANE mutations in cyclic and

- severe congenital neutropenia: genetics and pathophysiology. Hematol Oncol Clin North Am 2013; 27:19-41; vii.

This study comprehensively reviews SCN due to ELANE deficiency.

16. Horwitz MS, Duan Z, Korkmaz B, et al. Neutrophil elastase in cyclic and severe congenital neutropenia. Blood 2007; 109:1817-1824.

17. Massullo $P$, Druhan $L$, Bunnell $B A$, et al. Aberrant subcellular targeting of the G185R neutrophil elastase mutant associated with severe congenital neutropenia induces premature apoptosis of differentiating promyelocytes. Blood 2005; 105:3397-3404.

18. Li W, Feng $\mathrm{Y}$, Hao $\mathrm{C}$, et al. The BLOC interactomes form a network in endosomal transport. J Genet Genomics 2007; 34:669-682.

19. Kollner I, Sodeik B, Schreek S, et al. Mutations in neutrophil elastase causing congenital neutropenia lead to cytoplasmic protein accumulation and induction of the unfolded protein response. Blood 2006; 108:493-500.

20. Grenda DS, Murakami M, Ghatak J, et al. Mutations of the ELA2 gene found in patients with severe congenital neutropenia induce the unfolded protein response and cellular apoptosis. Blood 2007; 110:4179-4187.

21. Person RE, Li FQ, Duan $Z$, et al. Mutations in proto-oncogene GFI1 cause human neutropenia and target ELA2. Nat Genet 2003; 34:308-312.

22. Zarebski A, Velu CS, Baktula AM, et al. Mutations in growth factor independent-1 associated with human neutropenia block murine granulopoiesis through colony stimulating factor-1. Immunity 2008; 28:370-380.

23. Salipante SJ, Rojas ME, Korkmaz B, et al. Contributions to neutropenia from PFAAP5 (N4BP2L2), a novel protein mediating transcriptional repressor cooperation between Gfi1 and neutrophil elastase. Mol Cell Biol 2009; 29:4394-4405

24. Armistead PM, Wieder $\mathrm{E}$, Akande $\mathrm{O}$, et al. Cyclic neutropenia associated with $\mathrm{T}$ cell immunity to granulocyte proteases and a double de novo mutation in GFI1, a transcriptional regulator of ELANE. $\mathrm{Br} J$ Haematol 2010; 150:716-719.

25. Kostmann R. Infantile genetic agranulocytosis; agranulocytosis infantilis hereditaria. Acta Paediatr Suppl 1956; 45:1-78.

26. Klein $\mathrm{C}$, Grudzien M, Appaswamy G, et al. HAX1 deficiency causes autosomal recessive severe congenital neutropenia (Kostmann disease). Nat Genet 2007; 39:86-92.

27. Carlsson G, Fasth $A$. Infantile genetic agranulocytosis, morbus Kostmann: presentation of six cases from the original 'Kostmann family' and a review. Acta Paediatr 2001; 90:757-764.

28. Germeshausen $M$, Grudzien $M$, Zeidler $C$, et al. Novel HAX1 mutations in patients with severe congenital neutropenia reveal isoform-dependent genotype-phenotype associations. Blood 2008; 111:4954-4957.

29. Carlsson $G$, van't Hooft I, Melin M, et al. Central nervous system involvement in severe congenital neutropenia: neurological and neuropsychological abnormalities associated with specific HAX1 mutations. J Intern Med 2008; 264:388-400. 
30. Suzuki Y, Demoliere C, Kitamura D, et al. HAX-1, a novel intracellular protein, localized on mitochondria, directly associates with HS1, a substrate of Src family tyrosine kinases. J Immunol 1997; 158:2736-2744.

31. Chao JR, Parganas E, Boyd K, et al. Hax1-mediated processing of HtrA2 by Parl allows survival of lymphocytes and neurons. Nature 2008; 452:98-102.

32. Cilenti L, Soundarapandian MM, Kyriazis GA, et al. Regulation of HAX-1 antiapoptotic protein by Omi/HtrA2 protease during cell death. J Biol Chem 2004; 279:50295-50301.

33. Kang $Y$ J, Jang $M$, Park $Y K$, et al. Molecular interaction between HAX-1 and XIAP inhibits apoptosis. Biochem Biophys Res Commun 2010; 393:794799.

34. Vafiadaki E, Arvanitis DA, Pagakis $\mathrm{SN}$, et al. The antiapoptotic protein HAX-1 interacts with SERCA2 and regulates its protein levels to promote cell survival. Mol Biol Cell 2009; 20:306-318.

35. Hayee B, Antonopoulos A, Murphy EJ, et al. G6PC3 mutations are associated with a major defect of glycosylation: a novel mechanism for neutrophil dysfunction. Glycobiology 2011; 21:914-924.

36. Jun HS, Lee YM, Song KD, et al. G-CSF improves murine G6PC3-deficient neutrophil function by modulating apoptosis and energy homeostasis. Blood $2011 ; 117: 3881-3892$

37. Devriendt K, Kim AS, Mathijs G, et al. Constitutively activating mutation in WASP causes X-linked severe congenital neutropenia. Nat Genet 2001; 27:313-317.

38. Ancliff PJ, Blundell MP, Cory GO, et al. Two novel activating mutations in the Wiskott-Aldrich syndrome protein result in congenital neutropenia. Blood 2006; 108:2182-2189.

39. Beel K, Cotter MM, Blatny J, et al. A large kindred with X-linked neutropenia with an I294T mutation of the Wiskott-Aldrich syndrome gene. Br J Haematol 2009; 144:120-126

40. Moulding DA, Blundell MP, Spiller DG, et al. Unregulated actin polymerization by WASp causes defects of mitosis and cytokinesis in X-linked neutropenia. J Exp Med 2007; 204:2213-2224.

41. Westerberg LS, Meelu $P$, Baptista $M$, et al. Activating WASP mutations associated with $\mathrm{X}$-linked neutropenia result in enhanced actin polymerization, altered cytoskeletal responses, and genomic instability in lymphocytes. J Exp Med 2010; 207:1145-1152.

42. Vilboux T, Lev A, Malicdan MC, et al. A congenital neutrophil defect syndrome

m. associated with mutations in VPS45. N Engl J Med 2013; 369:54-65.

This study describes VPS45 deficiency and defective endosomal trafficking as a

novel pathogenic mechanism of SCN.

43. Chediak MM. New leukocyte anomaly of constitutional and familial character. Rev Hematol 1952; 7:362-367.

44. Higashi O. Congenital gigantism of peroxidase granules; the first case ever reported of qualitative abnormity of peroxidase. Tohoku J Exp Med 1954; 59:315-332.

45. Barbosa MD, Nguyen QA, Tchernev VT, et al. Identification of the homologous beige and Chediak-Higashi syndrome genes. Nature 1996; 382: 262-265.

46. Nagle DL, Karim MA, Woolf EA, et al. Identification and mutation analysis of the complete gene for Chediak-Higashi syndrome. Nat Genet 1996; 14: 307-311.

47. Bossi G, Griffiths GM. CTL secretory lysosomes: biogenesis and secretion of a harmful organelle. Semin Immunol 2005; 17:87-94.

48. Williams RL, Urbe S. The emerging shape of the ESCRT machinery. Nat Rev Mol Cell Biol 2007; 8:355-368.

49. Karim MA, Suzuki K, Fukai K, et al. Apparent genotype-phenotype correlation in childhood, adolescent, and adult Chediak-Higashi syndrome. Am J Med Genet 2002; 108:16-22.

50. Hermansky F, Pudlak P. Albinism associated with hemorrhagic diathesis and unusual pigmented reticular cells in the bone marrow: report of two cases with histochemical studies. Blood 1959; 14:162-169.

51. Wei ML. Hermansky-Pudlak syndrome: a disease of protein trafficking and organelle function. Pigment Cell Res 2006; 19:19-42.

52. Clark RH, Stinchcombe JC, Day A, et al. Adaptor protein 3-dependent microtubule-mediated movement of lytic granules to the immunological synapse. Nat Immunol 2003; 4:1111-1120.

53. Enders A, Zieger B, Schwarz $K$, et al. Lethal hemophagocytic lymphohistiocytosis in Hermansky-Pudlak syndrome type II. Blood 2006; 108:81-87.

54. Jessen B, Bode SF, Ammann S, et al. The risk of hemophagocytic lympho-

- histiocytosis in Hermansky-Pudlak syndrome type 2. Blood 2013; 121: 2943-2951.

This study establishes the relative risk of HLH in HPS2 and proposes that preemptive HSCTx is not justified for this entity.

55. Klein C, Philippe N, Le Deist F, et al. Partial albinism with immunodeficiency (Griscelli syndrome). J Pediatr 1994; 125:886-895.

56. Meeths M, Bryceson YT, Rudd E, et al. Clinical presentation of Griscelli syndrome type 2 and spectrum of RAB27A mutations. Pediatr Blood Cancer 2010; 54:563-572.

57. Van Gele M, Dynoodt P, Lambert J. Griscelli syndrome: a model system to study vesicular trafficking. Pigment Cell Melanoma Res 2009; 22:268282.

58. Ohbayashi N, Mamishi S, Ishibashi K, et al. Functional characterization of two RAB27A missense mutations found in Griscelli syndrome type 2. Pigment Cell Melanoma Res 2010; 23:365-374.
59. Bohn G, Allroth A, Brandes G, et al. A novel human primary immunodeficiency syndrome caused by deficiency of the endosomal adaptor protein p14. Nat Med 2007; 13:38-45

60. Lagresle-Peyrou C, Six EM, Picard C, et al. Human adenylate kinase 2 deficiency causes a profound hematopoietic defect associated with sensorineural deafness. Nat Genet 2009; 41:106-111.

61. Pannicke $U$, Honig $M$, Hess I, et al. Reticular dysgenesis (aleukocytosis) is caused by mutations in the gene encoding mitochondrial adenylate kinase 2 . Nat Genet 2009; 41:101-105.

62. Abdollahpour H, Appaswamy G, Kotlarz D, et al. The phenotype of human STK4 deficiency. Blood 2012; 119:3450-3457.

This study together with ref. [140] describes STK4 deficiency.

63. Crequer A, Picard C, Patin E, et al. Inherited MST1 deficiency underlies

- susceptibility to EV-HPV infections. PLoS One 2012; 7:e44010.

This study expands the phenotype of STK4 deficiency.

64. Nehme NT, Pachlopnik Schmid J, Debeurme F, et al. MST1 mutations in

- autosomal recessive primary immunodeficiency characterized by defective naive T-cell survival. Blood 2012; 119:3458-3468.

This study together with ref. [138] describes STK4 deficiency.

65. Boocock GR, Morrison JA, Popovic M, et al. Mutations in SBDS are associated with Shwachman-Diamond syndrome. Nat Genet 2003; 33: 97-101.

66. Austin KM, Gupta ML Jr, Coats SA, et al. Mitotic spindle destabilization and genomic instability in Shwachman-Diamond syndrome. J Clin Invest 2008; 118:1511-1518.

67. Raaijmakers $\mathrm{MH}$, Mukherjee $\mathrm{S}$, Guo $\mathrm{S}$, et al. Bone progenitor dysfunction induces myelodysplasia and secondary leukaemia. Nature 2010; 464:852857.

68. Dror Y, Donadieu J, Koglmeier J, et al. Draft consensus guidelines for diagnosis and treatment of Shwachman-Diamond syndrome. Ann N Y Acad Sci $2011 ; 1242: 40-55$.

69. Zuelzer WW. Myelokathexis: a new form of chronic granulocytopenia. Report of a case. N Engl J Med 1964; 270:699-704.

70. Hernandez PA, Gorlin RJ, Lukens JN, et al. Mutations in the chemokine receptor gene CXCR4 are associated with WHIM syndrome, a combined immunodeficiency disease. Nat Genet 2003; 34:70-74.

71. Balabanian $K$, Lagane $B$, Pablos JL, et al. WHIM syndromes with different genetic anomalies are accounted for by impaired CXCR4 desensitization to CXCL12. Blood 2005; 105:2449-2457.

72. Lagane $\mathrm{B}$, Chow $\mathrm{KY}$, Balabanian $\mathrm{K}$, et al. CXCR4 dimerization and betaarrestin-mediated signaling account for the enhanced chemotaxis to CXCL12 in WHIM syndrome. Blood 2008; 112:34-44.

73. McDermott $\mathrm{DH}$, Liu $\mathrm{Q}$, Ulrick J, et al. The CXCR4 antagonist plerixafor corrects panleukopenia in patients with WHIM syndrome. Blood 2011; 118:4957-4962.

74. Clericuzio $\mathrm{C}$, Hoyme $\mathrm{H}$, Aase J. Immune deficient poikiloderma: a new genodermatosis. Am J Hum Genet 1991; 86 (1):A661.

75. Volpi L, Roversi G, Colombo EA, et al. Targeted next-generation sequencing appoints c16orf57 as clericuzio-type poikiloderma with neutropenia gene. Am J Hum Genet 2010; 86:72-76.

76. Arnold AW, Itin PH, Pigors $\mathrm{M}$, et al. Poikiloderma with neutropenia: a novel C16orf57 mutation and clinical diagnostic criteria. Br J Dermatol 2010; 163:866-869.

77. Mroczek S, Krwawicz J, Kutner J, et al. C16orf57, a gene mutated in

- poikiloderma with neutropenia, encodes a putative phosphodiesterase responsible for the U6 snRNA 3' end modification. Genes Dev 2012; 26: $1911-1925$.

This study describes the USB1 gene product as a putative phosphodiesterase involved in snRNA stability and proposes telomere maintenance as a common pathogenic mechanism of PN, RTS and dyskeratosis congenita.

78. McKusick VA, Eldridge R, Hostetler JA, et al. Dwarfism in the Amish. li. Cartilage-hair hypoplasia. Bull Johns Hopkins Hosp 1965; 116:285-326.

79. Makitie O. Cartilage-hair hypoplasia in Finland: epidemiological and genetic aspects of 107 patients. J Med Genet 1992; 29:652-655.

80. Ridanpaa $\mathrm{M}$, van Eenennaam $\mathrm{H}$, Pelin $\mathrm{K}$, et al. Mutations in the RNA component of RNase MRP cause a pleiotropic human disease, cartilagehair hypoplasia. Cell 2001; 104:195-203.

81. Makitie O, Juvonen E, Dunkel L, et al. Anemia in children with cartilage-hair hypoplasia is related to body growth and to the insulin-like growth factor system. J Clin Endocrinol Metab 2000; 85:563-568.

82. Makitie O, Pukkala E, Teppo L, Kaitila I. Increased incidence of cancer in patients with cartilage-hair hypoplasia. J Pediatr 1999; 134:315-318.

83. Bordon V, Gennery AR, Slatter MA, et al. Clinical and immunologic outcome of patients with cartilage hair hypoplasia after hematopoietic stem cell transplantation. Blood 2010; 116:27-35.

84. de la Fuente MA, Recher M, Rider NL, et al. Reduced thymic output, cell cycle abnormalities, and increased apoptosis of $\mathrm{T}$ lymphocytes in patients with cartilage-hair hypoplasia. J Allergy Clin Immunol 2011; 128:139146.

85. Winkelstein JA, Marino MC, Ochs $\mathrm{H}$, et al. The X-linked hyper-lgM syndrome: clinical and immunologic features of 79 patients. Medicine (Baltimore) 2003; 82:373-384.

86. Kracker $S$, Gardes $P$, Mazerolles F, Durandy A. Immunoglobulin class switch recombination deficiencies. Clin Immunol 2010; 135:193-203. 
87. Barth PG, Scholte HR, Berden JA, et al. An X-linked mitochondrial disease affecting cardiac muscle, skeletal muscle and neutrophil leucocytes. J Neurol Sci 1983; 62:327-355.

88. Barth PG, Valianpour F, Bowen VM, et al. X-linked cardioskeletal myopathy and neutropenia (Barth syndrome): an update. Am J Med Genet A 2004; 126A:349-354.

89. Kolehmainen J, Black GC, Saarinen A, et al. Cohen syndrome is caused by mutations in a novel gene, $\mathrm{COH} 1$, encoding a transmembrane protein with a presumed role in vesicle-mediated sorting and intracellular protein transport. Am J Hum Genet 2003; 72:1359-1369.

90. Chandler KE, Kidd A, Al-Gazali L, et al. Diagnostic criteria, clinical characteristics, and natural history of Cohen syndrome. J Med Genet 2003; 40:233-241.

91. El Chehadeh S, Aral B, Gigot N, et al. Search for the best indicators for the presence of a VPS13B gene mutation and confirmation of diagnostic criteria in a series of 34 patients genotyped for suspected Cohen syndrome. J Med Genet 2010; 47:549-553.

92. Hahn CN, Chong CE, Carmichael CL, et al. Heritable GATA2 mutations associated with familial myelodysplastic syndrome and acute myeloid leukemia. Nat Genet 2011; 43:1012-1017.

93. Ostergaard $P$, Simpson MA, Connell FC, et al. Mutations in GATA2 cause primary lymphedema associated with a predisposition to acute myeloid leukemia (Emberger syndrome). Nat Genet 2011; 43:929-931.

94. Hsu AP, Sampaio EP, Khan J, et al. Mutations in GATA2 are associated with the autosomal dominant and sporadic monocytopenia and mycobacterial infection (MonoMAC) syndrome. Blood 2011; 118:2653-2655.

95. Emberger JM, Navarro M, Dejean M, Izarn P. Deaf-mutism, lymphedema of the lower limbs and hematological abnormalities (acute leukemia, cytopenia) with autosomal dominant transmission. J Genet Hum 1979; 27:237-245.

96. Pasquet $\mathrm{M}$, Bellanne-Chantelot $\mathrm{C}$, Tavitian $\mathrm{S}$, et al. High frequency of GATA2

- mutations in patients with mild chronic neutropenia evolving to MonoMac syndrome, myelodysplasia, and acute myeloid leukemia. Blood 2013; $121: 822-829$.

This study describes GATA2 deficiency as the cause of MonoMac syndrome and congenital MDS.

97. Beaudet AL, Anderson DC, Michels VV, et al. Neutropenia and impaired neutrophil migration in type IB glycogen storage disease. J Pediatr 1980; 97:906-910.

98. Gerin I, Veiga-da-Cunha M, Achouri Y, et al. Sequence of a putative glucose 6 -phosphate translocase, mutated in glycogen storage disease type $\mathrm{lb}$. FEBS Lett 1997; 419:235-238.

99. Narisawa K, Tada K, Kuzuya T. Neutropenia in type IB glycogen storage disease. J Pediatr 1981; 99:334-335.

100. Pearson HA, Lobel JS, Kocoshis SA, et al. A new syndrome of refractory sideroblastic anemia with vacuolization of marrow precursors and exocrine pancreatic dysfunction. J Pediatr 1979; 95:976-984.

101. Seneca S, De Meirleir L, De Schepper J, et al. Pearson marrow pancreas syndrome: a molecular study and clinical management. Clin Genet 1997; 51:338-342.

102. Wong LJ. Molecular genetics of mitochondrial disorders. Dev Disabil Res Rev 2010; 16:154-162.

103. Boztug K, Klein C. Genetics and pathophysiology of severe congenital neutropenia syndromes unrelated to neutrophil elastase. Hematol Oncol Clin North Am 2013; 27:43-60; vii.

This study comprehensively reviews SCN other than ELANE deficiency.

104. Skokowa J, Welte K. Dysregulation of myeloid-specific transcription factors in congenital neutropenia. Ann N Y Acad Sci 2009; 1176:94-100

105. Manroe BL, Weinberg AG, Rosenfeld CR, Browne R. The neonatal blood count in health and disease. I. Reference values for neutrophilic cells. J Pediatr 1979; 95:89-98.

106. Sennels HP, Jorgensen HL, Hansen AL, et al. Diurnal variation of hematology parameters in healthy young males: the Bispebjerg study of diurnal variations. Scand J Clin Lab Invest 2011; 71:532-541.

107. Donadieu J, Beaupain B, Mahlaoui N, Bellanne-Chantelot C. Epidemiology of - congenital neutropenia. Hematol Oncol Clin North Am 2013; 27:1-17; vii.

This study comprehensively reviews epidemiolgic aspects of congenital neutropenia.

108. Donadieu J, Leblanc T, Bader Meunier B, et al. Analysis of risk factors for myelodysplasias, leukemias and death from infection among patients with congenital neutropenia. Experience of the French Severe Chronic Neutropenia Study Group. Haematologica 2005; 90:45-53.

109. Rosenberg PS, Alter BP, Bolyard AA, et al. The incidence of leukemia and mortality from sepsis in patients with severe congenital neutropenia receiving long-term G-CSF therapy. Blood 2006; 107:4628-4635.

110. Bonilla MA, Gillio AP, Ruggeiro $M$, et al. Effects of recombinant human granulocyte colony-stimulating factor on neutropenia in patients with congenital agranulocytosis. N Engl J Med 1989; 320:1574-1580.

111. Dale DC, Bonilla MA, Davis MW, et al. A randomized controlled phase III trial of recombinant human granulocyte colony-stimulating factor (filgrastim) for treatment of severe chronic neutropenia. Blood 1993; 81:24962502.

112. Klein C. Genetic defects in severe congenital neutropenia: emerging insights into life and death of human neutrophil granulocytes. Annu Rev Immunol $2011 ; 29: 399-413$
113. Klebanoff SJ, Kettle AJ, Rosen $\mathrm{H}$, et al. Myeloperoxidase: a front-line defender

- against phagocytosed microorganisms. J Leukoc Biol 2013; 93:185198.

This study comprehensively reviews MPD.

114. Holland SM. Chronic granulomatous disease. Hematol Oncol Clin North Am

- 2013; 27:89-99; viii.

This study comprehensively reviews CGD

115. van de Vijver E, van den Berg TK, Kuijpers TW. Leukocyte adhesion

- deficiencies. Hematol Oncol Clin North Am 2013; 27:101-116; viii.

This study comprehensively reviews LAD.

116. Broun GO Jr, Herbig FK, Hamilton JR. Leukopenia in Negroes. N Engl J Med 1966; 275:1410-1413.

117. Haddy TB, Rana SR, Castro O. Benign ethnic neutropenia: what is a normal absolute neutrophil count? J Lab Clin Med 1999; 133:15-22.

118. Hsieh MM, Everhart JE, Byrd-Holt DD, et al. Prevalence of neutropenia in the U.S. population: age, sex, smoking status, and ethnic differences. Ann Intern Med 2007; 146:486-492.

119. Denic S, Showqi S, Klein $C$, et al. Prevalence, phenotype and inheritance of benign neutropenia in Arabs. BMC Blood Disord 2009; 9:3.

120. Papadaki HA, Xylouri I, Coulocheri S, et al. Prevalence of chronic idiopathic neutropenia of adults among an apparently healthy population living on the island of Crete. Ann Hematol 1999; 78:293-297.

121. Kourtis AP, Hudgens MG, Kayira D. Neutrophil count in African mothers

- and newborns and HIV transmission risk. N Engl J Med 2012; 367:22602262.

This study estblishes a relationship between the Duffy null trait and an increased susceptibility to perinatal HIV infection.

122. Lee JS, Frevert CW, Wurfel MM, et al. Duffy antigen facilitates movement of chemokine across the endothelium in vitro and promotes neutrophil transmigration in vitro and in vivo. J Immunol 2003; 170:5244-5251.

123. Lee JS, Wurfel MM, Matute-Bello G, et al. The Duffy antigen modifies systemic and local tissue chemokine responses following lipopolysaccharide stimulation. J Immunol 2006; 177:8086-8094

124. Nalls MA, Couper DJ, Tanaka $T$, et al. Multiple loci are associated with white blood cell phenotypes. PLoS Genet 2011; 7:e1002113.

125. Crosslin DR, McDavid A, Weston $N$, et al. Genetic variants associated with

- the white blood cell count in 13,923 subjects in the eMERGE Network. Hum Genet 2012; 131:639-652.

Together with ref. [28], this article establishes the association of particular genetic loci with total white blood cell counts and subtype counts.

126. Germeshausen $M$, Deerberg $S$, Peter $Y$, et al. The spectrum of ELANE

- mutations and their implications in severe congenital and cyclic neutropenia. Hum Mutat 2013; 34:905-914.

This study shows that there is only a partial genotype-phenotype correlation for particular ELANE mutations with $\mathrm{SCN}$ or $\mathrm{CyN}$ and that the risk of leukemogenesis correlates more with disease severity than with a specific mutation.

127. Dong F, Brynes RK, Tidow N, et al. Mutations in the gene for the granulocyte colony-stimulating-factor receptor in patients with acute myeloid leukemia preceded by severe congenital neutropenia. N Engl J Med 1995; 333:487493

128. Carlsson G, Aprikyan AA, Ericson KG, et al. Neutrophil elastase and granulocyte colony-stimulating factor receptor mutation analyses and leukemia evolution in severe congenital neutropenia patients belonging to the original Kostmann family in northern Sweden. Haematologica 2006; 91:589-595.

129. Janoff A, Scherer J. Mediators of inflammation in leukocyte lysosomes. IX. Elastinolytic activity in granules of human polymorphonuclear leukocytes. J Exp Med 1968; 128:1137-1155.

130. Gullberg U, Bengtsson N, Bulow $E$, et al. Processing and targeting of granule proteins in human neutrophils. J Immunol Methods 1999; 232:201-210.

131. Adkison AM, Raptis SZ, Kelley DG, Pham CT. Dipeptidyl peptidase I activates neutrophil-derived serine proteases and regulates the development of acute experimental arthritis. J Clin Invest 2002; 109:363-371.

132. Korkmaz B, Horwitz MS, Jenne DE, Gauthier F. Neutrophil elastase, proteinase 3 , and cathepsin $G$ as therapeutic targets in human diseases. Pharmacol Rev 2010; 62:726-759.

133. Hunter MG, Druhan $\sqcup$, Massullo PR, Avalos BR. Proteolytic cleavage of granulocyte colony-stimulating factor and its receptor by neutrophil elastase induces growth inhibition and decreased cell surface expression of the granulocyte colony-stimulating factor receptor. Am J Hematol 2003; 74: $149-155$.

134. Ye S, Goldsmith EJ. Serpins and other covalent protease inhibitors. Curr Opin Struct Biol 2001; 11:740-745.

135. Horwitz M, Benson KF, Duan Z, et al. Role of neutrophil elastase in bone marrow failure syndromes: molecular genetic revival of the chalone hypothesis. Curr Opin Hematol 2003; 10:49-54.

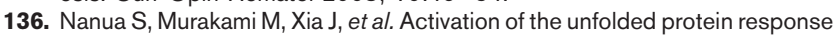
is associated with impaired granulopoiesis in transgenic mice expressing mutant Elane. Blood 2011; 117:3539-3547.

137. Beekman R, Valkhof MG, Sanders MA, et al. Sequential gain of mutations in

- severe congenital neutropenia progressing to acute myeloid leukemia. Blood 2012; 119:5071-5077.

This study shows that leukemogenesis in SCN is a multistep process with abnormal G-CSF signalling as an important driver of leukemic transformation. 
138. Hock $\mathrm{H}$, Hamblen MJ, Rooke HM, et al. Intrinsic requirement for zinc finger transcription factor Gfi-1 in neutrophil differentiation. Immunity 2003; 18:109-120.

139. Karsunky $H$, Zeng $H$, Schmidt $T$, et al. Inflammatory reactions and severe neutropenia in mice lacking the transcriptional repressor Gfi1. Nat Genet 2002; 30:295-300.

140. Rathinam C, Geffers R, Yucel R, et al. The transcriptional repressor Gfi1 controls STAT3-dependent dendritic cell development and function. Immunity $2005 ; 22: 717-728$

141. Rathinam C, Klein C. Transcriptional repressor Gfi1 integrates cytokinereceptor signals controlling B-cell differentiation. PLoS One 2007; 2:e306.

142. Zhu J, Guo L, Min B, et al. Growth factor independent- 1 induced by IL-4 regulates Th2 cell proliferation. Immunity 2002; 16:733-744.

143. Zhu J, Davidson TS, Wei G, et al. Down-regulation of Gfi-1 expression by TGF-beta is important for differentiation of Th17 and CD103+ inducible regulatory T cells. J Exp Med 2009; 206:329-341.

144. Horman SR, Velu CS, Chaubey $A$, et al. Gfi1 integrates progenitor versus granulocytic transcriptional programming. Blood 2009; 113:5466-5475.

145. Zhuang D, Qiu Y, Kogan SC, Dong F. Increased CCAAT enhancer-binding protein epsilon (C/EBPepsilon) expression and premature apoptosis in myeloid cells expressing Gfi-1 N382S mutant associated with severe congenital neutropenia. J Biol Chem 2006; 281:10745-10751.

146. Velu CS, Baktula AM, Grimes HL. Gfi1 regulates miR-21 and miR-196b to control myelopoiesis. Blood 2009; 113:4720-4728.

147. Marteijn JA, van der Meer LT, van Emst L, et al. Gfi1 ubiquitination and proteasomal degradation is inhibited by the ubiquitin ligase Triad1. Blood 2007; 110:3128-3135.

148. Xia J, Bolyard AA, Rodger $E$, et al. Prevalence of mutations in ELANE, GFI1, HAX1, SBDS, WAS and G6PC3 in patients with severe congenital neutropenia. Br J Haematol 2009; 147:535-542.

149. Carlsson $G$, Elinder $G$, Malmgren $H$, et al. Compound heterozygous HAX1 mutations in a Swedish patient with severe congenital neutropenia and no neurodevelopmental abnormalities. Pediatr Blood Cancer 2009; 53:11431146.

150. Xue SL, Li JL, Zou JY, et al. A novel compound heterozygous HAX1 mutation

n. in a Chinese patient with severe congenital neutropenia and chronic myelomonocytic leukemia transformation but without neurodevelopmental abnormalities. Haematologica 2012; 97:318-320.

This study challanges the view that $H A X 1$ mutations affecting both isoforms $\mathrm{A}$ and

$B$ cause neuropathology.

151. Sharp TV, Wang HW, Koumi A, et al. K15 protein of Kaposi's sarcomaassociated herpesvirus is latently expressed and binds to $\mathrm{HAX}-1$, a protein with antiapoptotic function. J Virol 2002; 76:802-816.

152. Dufva M, Olsson $M$, Rymo L. Epstein-Barr virus nuclear antigen 5 interacts with $\mathrm{HAX}-1$, a possible component of the B-cell receptor signalling pathway. J Gen Virol 2001; 82:1581-1587.

153. Matsuda G, Nakajima $K$, Kawaguchi $Y$, et al. Epstein-Barr virus (EBV) nuclear antigen leader protein (EBNA-LP) forms complexes with a cellular antiapoptosis protein $\mathrm{Bcl}-2$ or its EBV counterpart BHRF1 through HS1-associated protein X-1. Microbiol Immunol 2003; 47:91-99.

154. Yedavalli VS, Shih HM, Chiang YP, et al. Human immunodeficiency virus type $1 \mathrm{Vpr}$ interacts with antiapoptotic mitochondrial protein HAX-1. J Virol 2005; 79:13735-13746.

155. Modem S, Reddy TR. An antiapoptotic protein, Hax-1, inhibits the HIV-1 rev function by altering its sub-cellular localization. J Cell Physiol 2008; 214 : 14-19.
156. Banerjee $A$, Saito $K$, Meyer $K$, et al. Hepatitis $C$ virus core protein and cellular protein HAX-1 promote 5-fluorouracil-mediated hepatocyte growth inhibition. J Virol 2009; 83:9663-9671.

157. Cavnar PJ, Berthier E, Beebe DJ, Huttenlocher A. Hax1 regulates neutrophil adhesion and motility through RhoA. J Cell Biol 2011; 193:465473.

158. Sarnowska E, Grzybowska EA, Sobczak K, et al. Hairpin structure within the 3'UTR of DNA polymerase beta mRNA acts as a posttranscriptional regulatory element and interacts with Hax-1. Nucleic Acids Res 2007; 35: 5499-5510.

159. Boztug K, Appaswamy G, Ashikov A, et al. A syndrome with congenital neutropenia and mutations in G6PC3. N Engl J Med 2009; 360:32-43.

160. Boztug K, Rosenberg PS, Dorda M, et al. Extended spectrum of human

- glucose-6-phosphatase catalytic subunit 3 deficiency: novel genotypes and phenotypic variability in severe congenital neutropenia. J Pediatr 2012; 160:679-683; e2.

This study extends the genotypic and phenotypic spectrum of G6PC3 deficiency and shows that this SCN entity might not have an increased risk of MDS/AML.

161. Hutton JC, O'Brien RM. Glucose-6-phosphatase catalytic subunit gene family. J Biol Chem 2009; 284:29241-29245.

162. Boztug K, Klein C. Novel genetic etiologies of severe congenital neutropenia. Curr Opin Immunol 2009; 21:472-480.

163. Jun HS, Lee YM, Cheung YY, et al. Lack of glucose recycling between endoplasmic reticulum and cytoplasm underlies cellular dysfunction in glucose-6-phosphatase-beta-deficient neutrophils in a congenital neutropenia syndrome. Blood 2010; 116:2783-2792.

164. Maurer U, Charvet C, Wagman AS, et al. Glycogen synthase kinase-3 regulates mitochondrial outer membrane permeabilization and apoptosis by destabilization of MCL-1. Mol Cell 2006; 21:749-760.

165. Zhao Y, Altman BJ, Coloff JL, et al. Glycogen synthase kinase 3alpha and 3beta mediate a glucose-sensitive antiapoptotic signaling pathway to stabilize Mcl-1. Mol Cell Biol 2007; 27:4328-4339.

166. Ochs HD, Filipovich $A H, V e y s ~ P$, et al. Wiskott-Aldrich syndrome: diagnosis, clinical and laboratory manifestations, and treatment. Biol Blood Marrow Transplant 2009; 15:84-90.

167. Albert MH, Bittner TC, Nonoyama $S$, et al. X-linked thrombocytopenia (XLT) due to WAS mutations: clinical characteristics, long-term outcome, and treatment options. Blood 2010; 115:3231-3238.

168. Dustin ML, Depoil D. New insights into the $T$ cell synapse from single molecule techniques. Nat Rev Immunol 2011; 11:672-684.

169. Thrasher AJ, Burns SO. WASP: a key immunological multitasker. Nat Rev Immunol 2010; 10:182-192.

170. Kinchen JM, Ravichandran KS. Phagosome maturation: going through the acid test. Nat Rev Mol Cell Biol 2008; 9:781-795.

171. Rahajeng J, Caplan S, Naslavsky N. Common and distinct roles for the binding partners Rabenosyn-5 and Vps45 in the regulation of endocytic trafficking in mammalian cells. Exp Cell Res 2010; 316:859-874.

172. Erickson RP. Southwestern Athabaskan (Navajo and Apache) genetic diseases. Genet Med 1999; 1:151-157.

173. Walne AJ, Vulliamy $T$, Beswick R, et al. Mutations in $C 16$ orf57 and normallength telomeres unify a subset of patients with dyskeratosis congenita, poikiloderma with neutropenia and Rothmund-Thomson syndrome. Hum Mol Genet 2010; 19:4453-4461.

174. Wang LL, Levy ML, Lewis RA, et al. Clinical manifestations in a cohort of 41 Rothmund-Thomson syndrome patients. Am J Med Genet 2001; 102: $11-17$. 